\title{
Slaughter of poultry during the epidemic of avian influenza in the Netherlands in 2003
}

\author{
M. A. Gerritzen, E. LamboolJ, J. A. Stegeman, B. M. Spruijt
}

\begin{abstract}
During an outbreak of avian influenza in the Netherlands in spring 2003, the disease was controlled by destroying all the poultry on the infected farms and on all the farms within a radius of $\mathbf{3} \mathbf{~ k m}$. In total, 30 million birds were killed on 1242 farms and in more than $\mathbf{8 0 0 0}$ hobby flocks, by using mobile containers filled with carbon dioxide, mobile electrocution lines and by gassing whole poultry houses with carbon monoxide or carbon dioxide. Observations of these methods were used to compare their effectiveness and capacity, and their effects on the welfare of the birds. Gassing whole poultry houses had a much greater capacity than mobile equipment, and catching live birds to bring them to a mobile killing device caused extra stress and could cause pain due to injuries inflicted when catching and handling them. Gassing whole poultry houses with carbon monoxide requires strict safety regulations and, therefore, gassing with carbon dioxide was considered preferable. However, this method is not suited to all types of housing, and in these circumstances mobile killing devices were a useful alternative.
\end{abstract}

IN spring 2003 the Dutch poultry industry was plagued by an outbreak of avian influenza, the control of which, as with other notifiable diseases, is defined by EU Directive 92/40/EEC (Anon 1992). Article 5 of this directive states that once the disease has been officially confirmed, all poultry on the holding should be killed on the premises, without delay, and in a way that minimises the risk of spreading the disease. Until 1994, poultry flocks were culled in their houses with hydrogen cyanide. However, because of the risks to people and the severe convulsions suffered by the birds before they became unconscious this method is no longer recommended (Scientific Veterinary Committee 1997), and hydrogen cyanide is no longer available in the Netherlands.

All the birds on a premises can be killed either inside or outside their houses. Killing them inside their houses reduces the risk of spreading disease during their movement to a killing device outside; moreover, killing them inside their houses with a lethal concentration of gas or with a toxic agent in the feed or drinking water avoids the stress produced by catching and transporting them. One problem when killing whole houses of birds simultaneously is the control of the killing process and the survival rate. Killing birds by bringing them to a killing device provides an opportunity to control the process for individual birds. Mobile killing equipment with a large capacity can be based upon gas or electricity. An advantage of electrocution is that death occurs immediately provided a sufficiently high current is applied; a disadvantage is that living birds have to be handled and shackled before they are electrocuted, a stressful process that can easily result in severe injuries such as broken bones (Knowles and Broom 1990). With a gas-killing device the birds do not have to be restrained individually, which is a major welfare advantage compared with electrocution, but they do have to be caught. Furthermore, the time required to induce unconsciousness and death, and the level of discomfort before loss of consciousness depends on the gassing method and the gas used. Gas killing methods are of two types. In the first, the birds are brought directly into contact with a high concentration of gas, resulting in the rapid induction of unconsciousness and death, which, however, is often accompanied by excitation (Raj and others 1992, Danneman and others 1997). In the second approach, the birds are brought into a relatively low concentration of an anaesthetic gas, the concentration of which is subsequently increased to a lethal level; by this method the induction of unconsciousness is prolonged but relatively smooth (Coenen and others 1995, Lambooij and others 1999).

During the 2003 epidemic of avian influenza in the Netherlands, contiguous culling by electrocution or differ- ent gassing methods was used to eliminate the disease. When large-scale on-farm culling is applied it is important that not only are all the birds killed, but also that any unpleasant, painful or frightening experiences before they lose consciousness should be minimised; the time needed to render the birds unconscious and thus the duration of these negative effects is therefore of major importance in terms of the birds' welfare. This paper describes observations of the methods used to kill large numbers of birds, with particular emphasis on gassing whole houses. The objective was to obtain an insight into the suitability of these methods, as judged by their efficacy in killing the birds and their effects on the birds' welfare.

\section{MATERIALS AND METHODS}

\section{Killing birds outside their houses}

Gas killing devices Several mobile types of gas killing device were used during the epidemic. They differed in size and operating efficiency, but all of them were filled with a high concentration of carbon dioxide before the birds were placed in them. In the smallest systems, the birds were caught and crated in their houses, and the crates were placed in the prefilled gas chamber. Other systems used containers varying in size from approximately $2 \mathrm{~m}^{3}$ to $35 \mathrm{~m}^{3}$. In these systems the birds were put into the container through a hatch in the top and plunged directly into a high concentration of carbon dioxide. The birds were kept in the gas containers long enough to ensure that they did not survive. All the mobile gas-killing systems were easy to use and incorporated a unit for controlling the concentration of carbon dioxide.

Electrocution The mobile electrocution equipment consisted of a water bath and a closed-loop shackling line. The capacity of the equipment varied with the length of the shackling loop and the size of the power supply used; lines with a 220 or $400 \mathrm{~V} \mathrm{AC}$ power supply were used. By increasing the power that was available to the water bath, more birds could be immersed while ensuring that there was sufficient current to kill all of them.

\section{Killing birds in their houses}

Different gasses and gassing methods were used to kill the birds in their houses. In all of them the doors, windows and ventilation slats of the houses were covered with plastic and taped to prevent leakage. Tubes connected to the gas containers outside the houses were brought inside at different positions, and after the ventilation had been switched off and the lights had been dimmed the supply of gas was switched on. 
Carbon monoxide Carbon monoxide was used in all the common types of housing, such as floor housing with litter and wire, battery-cage houses between three and seven cages in height, and houses with free-moving birds at different levels. The gas was supplied until a concentration of approximately 1.5 to 2 per cent carbon monoxide in the air was achieved. The concentrations of carbon monoxide were measured inside and outside the house by a fire brigade unit, and for safety reasons, access to within $25 \mathrm{~m}$ of the house was forbidden. The six farms where this method was used were inspected after the safety officer had given permission.

Carbon dioxide Carbon dioxide was supplied either as a cold liquid or as preheated gas. The cold liquid was supplied either by direct injection through nozzles, or by allowing it to leak from holes in the supply tubes. Both methods were applied in different types and sizes of houses, including floor housing, housing at different levels and battery-cage systems.

In the direct injection method, liquid carbon dioxide was pumped at a pressure of 20 bars through tubing fitted with specially shaped nozzles. The number and position of the injection nozzles depended on the type of housing; in large, tall housing such as multiple level systems, the nozzles were placed at the different floor levels; in high battery-cage systems they were located on the ceiling to allow downward injection; in floor and smaller battery-cage housing they were located on the floor injecting upwards. An opening was made in the roof to facilitate the escape of air. The high injection pressure and the environmental temperature within the house $\left(30\right.$ to $\left.35^{\circ} \mathrm{C}\right)$ resulted in the carbon dioxide evaporating directly from the nozzles into the air.

In the second method, liquid carbon dioxide was pumped through tubing with a diameter of $10 \mathrm{~cm}$ that had small holes in the metal connecting flanges, from which the gas vaporised due to the ambient temperature into the house. The concentration of carbon dioxide was not measured, but the quantity required to reach a concentration of 40 per cent was calculated by assuming that $1000 \mathrm{~kg}$ liquid carbon dioxide would provide $500 \mathrm{~m}^{3}$ of gas.

In the method using preheated carbon dioxide, the cold gas was heated to 40 to $50^{\circ} \mathrm{C}$ and injected into the house through tubing $10 \mathrm{~cm}$ in diameter. Sound-muffling equipment was added to the end of the tubing to reduce the possible stress to the birds from the noise.

\section{Observations}

The following general observations were made to assess the efficacy of the different methods and their impact on the welfare of the birds. They were made after the atmospheric conditions in the houses had returned to normal.

The time taken to apply a method was measured either as the time from starting the introduction of the gas to reaching the required concentration, or as the time from catching the birds and taking them to the killing device until they had been killed. The percentage of birds surviving the procedure was recorded. When whole houses of birds were gassed, the distribution of the dead birds in the house was recorded as an indicator of panic, fear or attempts to escape. In addition, the positions of individual birds were recorded as an indication of whether they had suffered convulsions and the percentage of birds lying on their back was calculated. Convulsive behaviour that starts after the loss of consciousness is not a welfare problem for the birds involved, but other birds in the house may be frightened by the behaviour. The convulsive behaviour may also affect the efficiency of the killing process by disturbing the concentration of the gas.

The observations were related to the method of killing and the type of housing. For example, in battery-cage systems the distribution of birds through the building was irrelevant.

\begin{tabular}{|c|c|c|c|c|c|}
\hline \multirow{2}{*}{ Method } & \multicolumn{2}{|c|}{ Houses } & \multirow[t]{2}{*}{$\begin{array}{c}\text { Mean (range) } \\
\text { number } \\
\text { of birds } \\
(\times 1000)\end{array}$} & $\begin{array}{c}\text { Mean (range) } \\
\text { time } \\
\text { taken } \\
\text { (minutes) }^{\dagger}\end{array}$ & \multirow[t]{2}{*}{$\begin{array}{c}\text { Mean (range) } \\
\text { dead birds } \\
\text { lying on } \\
\text { back }(\%)\end{array}$} \\
\hline & & & & & \\
\hline $\mathrm{CO}$ & 6 & 4 battery, 2 floor & 22 (4 to 35$)$ & 45 (30 to 120$)$ & 25 (1 to 50$)$ \\
\hline Liquid $\mathrm{CO}_{2}$ injected & 5 & $\begin{array}{l}1 \text { battery, } 2 \text { floor, } \\
2 \text { level }\end{array}$ & 15 (6 to 33$)$ & $30(10$ to 60$)$ & 1 (1 to 5$)$ \\
\hline $\begin{array}{c}\text { Liquid } \mathrm{CO}_{2} \text { introduced } \\
\text { through leaky pipes }\end{array}$ & 2 & 1 floor, 1 level & (6 to 12 ) & (60 to 60 ) & (1 to 2$)$ \\
\hline Heated $\mathrm{CO}_{2}$ & 5 & 2 battery, 3 floor & $9(6$ to 31$)$ & 30 (30 to 180$)$ & $3.5(1$ to 10$)$ \\
\hline
\end{tabular}

* Battery Battery-cages, Floor Floor housing on litter and wire, Level Free-moving birds at different levels

$\dagger$ Time taken from start of gas flow until required levels were reached

$\mathrm{CO}$ Carbon monoxide, $\mathrm{CO}_{2}$ Carbon dioxide

\section{RESULTS}

\section{Killing birds outside their houses}

There were large differences in capacity due to the different types and sizes of the husbandry systems. The time taken to catch the birds and transport them to the killing device varied. Crating the birds, as required for one of the mobile gas killing devices, also reduced the capacity. Moreover, capacity depended on the experience and the number of people that were available to catch and transport the birds to the killing device.

Gas killing devices The capacity of mobile gas killing devices depends on the size and number of gas containers available at the site. Wing flapping, jumping and heavy breathing were observed in a large percentage of birds directly after placing them in the gas containers, and lasted for 30 seconds to two minutes. The duration of these responses varied greatly depending on the number of animals that were brought into the killing device in a short time. No survivors were recorded in the mobile gas killing devices.

Electrocution The average current used for the electrocutions varied between 2 and $4 \mathrm{~A}$, depending on the voltage used and the number of birds entering the water bath at the same time. With a maximum of five birds entering the water bath at the same time the current ranged from 400 to 800 $\mathrm{mA}$ per birds. Although this current is normally sufficient to kill birds, not all of them were killed because some flapped their wings and raised their heads above the water and did not receive the full current; as a result, some of the birds were stunned but others remained fully conscious. No measures to reduce wing flapping were taken, but after an adjustment to the height of the water bath all the birds were killed.

\section{Killing birds in their houses}

Table 1 summarises the results of the observations made of the different methods.

Carbon monoxide In most cases the time taken to reach the required concentration of 1.5 per cent carbon monoxide varied from approximately 15 to 45 minutes, but it occasionally took up to one hour. Concentrations of up to $0 \cdot 2$ per cent carbon monoxide were measured outside the buildings. When the houses were constructed of wood, vocalisation and wing flapping against the walls were audible. Between 1 per cent and 50 per cent of the birds were found lying on their back, indicating that some birds had suffered convulsions. These convulsions were also visible on video recordings made during one of the trials, but it was impossible to determine whether the birds with convulsions were still conscious. However, it was clear that the first birds in a flock to be exposed had convulsions while most of the others were 
still conscious. At one farm with a house containing 35,500 birds, the concentration of carbon monoxide did not exceed 1.0 per cent, and after an hour approximately 20 per cent of the birds were still alive. The surviving birds were mainly found close to the gas inlet points and in the top cages of the battery. Immediately after this observation, the building was closed and the concentration was increased to 1.5 per cent and maintained for an hour. This resulted in 100 per cent mortality.

Carbon dioxide Liquid carbon dioxide was injected until a concentration of 40 per cent had been reached in the air of the house, and it was maintained for at least 30 minutes before the house was ventilated. The concentration of carbon dioxide was measured at the different levels where birds were present during the procedure. In the largest system, 5 per cent of the birds were found lying on their backs after gassing, but in the other four houses less than 1 per cent were found lying on their backs. Outside the buildings no sounds of agitation or convulsions could be heard. This technique creates a considerable amount of fog and reduces the temperature of the air in the building, but there were no visible signs that the reduced temperature affected the birds' behaviour. Because of the fog video recording was not possible. No survivors were observed in the five houses studied.

When liquid carbon dioxide was pumped into the houses through leaky tubes, the time taken to reach the required concentration was approximately one hour. The gas concentrations were not measured but calculated on the basis of the size of the houses. In the two houses treated by this method, 1 and 2 per cent of the birds were found lying on their backs. No sounds of agitation or convulsions were heard outside the houses, and no survivors were observed.

Preheated carbon dioxide was injected up to a calculated concentration of 40 per cent and maintained for at least 30 minutes; the concentration was measured occasionally by introducing a tube through a small opening at a ventilation point. It took 30 minutes to reach the required concentrations in the houses with birds on the floor, and up to $60 \mathrm{~min}$ utes for the two battery-cage systems. In the floor housing, between 1 per cent and 5 per cent of the birds were found on their backs, but in the battery-cage housing 10 per cent of the birds were found lying on their backs. In one of the batterycage systems, one bird survived.

\section{DISCUSSION}

To control the spread of highly virulent viruses such as avian influenza it is essential to implement a policy of contiguous culling as quickly as possible. During the 2003 epidemic in the Netherlands all the poultry on infected and suspected farms were destroyed, and all the flocks on the surrounding farms within a radius of $3 \mathrm{~km}$ were also killed. In total, 30 million birds on 1242 farms and more than 8000 backyard flocks were destroyed. It soon became evident that small mobile containers filled with carbon dioxide were inadequate, and to increase the killing capacity, mobile electrocution lines and large $35 \mathrm{~m}^{3}$ containers prefilled with the gas were used. The capacity of these devices depends not only on the technology but also on the capacity of the operators to catch and transport the birds from their houses to the containers. The capacity was further enlarged by using either carbon monoxide or carbon dioxide to gas whole houses of birds.

Infections with highly pathogenic avian influenza in poultry are frequently accompanied by severe physical problems that can cause up to 100 per cent mortality (Alexander 1995). For such infected flocks, killing can provide 'a humane death' or 'mercy killing' because the impact of the killing method on the welfare of the birds may be less severe than the suffering caused by the disease. However, because most of the birds killed during the epidemic were not infected, mercy killing did not apply to them. It was therefore important to choose a method with the least detrimental influence on the birds' welfare.

It is well known that catching and handling live birds can induce fear (Boissy 1995), and cause pain as a result of bruising and broken bones (Knowles and Broom 1990), particularly if the procedures are carried out by poorly trained staff. Furthermore, the shackling that is necessary with an electrocution line is potentially painful (Sparrey and Kettlewell 1994, Gentle and Tilson 2000). In addition, when birds are only stunned because they have not received sufficient current to kill them, some of them are probably still alive when they are placed in the killing chambers. It is therefore essential that the set-up and operation of an electrified water bath is adequately supervised to ensure that all the birds are dead when they are deshackled automatically. Exposure to high concentrations of carbon dioxide, as in mobile containers, induces breathlessness and can be painful (Danneman and others 1997). These adverse effects can be ameliorated by introducing the birds to a low anaesthetic concentration of the gas, followed by higher, lethal concentrations (Hoen and Lankhaar 1999, Coenen and others 2000), but the birds still have to be caught and transported to the container. The advantage of mobile electrocution lines and mobile gas units is their controllability, but they have a relatively small capacity and the live birds have to be caught and transported to them, with the attendant risk of spreading virus particles between the birds and human beings, and potentially more widely on air currents. Killing the birds inside their houses would probably reduce the spread of virus particles because no virus would be spread from the respiratory tract of dead birds. The openings in the houses created for gassing would not increase the spread of virus more than the normal ventilation openings. Gassing whole houses provides a large killing capacity and eliminates the need to handle live birds.

The use of carbon monoxide provided no smoother induction of unconsciousness than carbon dioxide, and the large-scale use of the gas requires strict safety regulations and procedures to minimise risks to personnel. During the gassing of whole houses the gas concentrations increased gradually and the birds tended to lose consciousness before they inhaled high and painful concentrations; the observations indicated that a gradual increase in the concentration of carbon dioxide induced few signs of severe convulsions. Danneman and others (1997) found that rats could be anaesthetised and euthanased humanely by a gradual increase in the concentration of carbon dioxide so that conscious animals were not exposed to concentrations above 70 per cent. Rhesus monkeys did not respond to noise and remained motionless in an atmosphere containing 17 per cent carbon dioxide, behaviour which was considered to indicate the onset of anaesthesia (Mattson and others 1972). Under experimental conditions broilers lost consciousness at 15 per cent carbon dioxide, and concentrations of 35 to 40 per cent, maintained for 30 minutes, led to 100 per cent mortality (Gerritzen and others 2004). In practice 40 per cent carbon dioxide maintained for 30 minutes appeared to be effective in killing all the birds.

The characteristics and availability of the different methods made it possible to choose the most suitable method for each poultry farm. The choice of the method was based on the size of the farm, for example, high capacity equipment for large farms, and on the type of housing, because not every poultry house is suitable for in-house gassing techniques. In addition to the capacity of the method and the type of housing involved, the birds' age and the safety requirements are essential in making a decision. Although whole-house gassing appeared to be effective there are points for concern. During the epidemic there were few controls on the procedure. There 
is little information about the efficacy and survival rate of the birds, or about the gas flows and build-up of its concentration. To reduce the birds' suffering to a minimum it is essential that the procedure applied to the chosen method is carefully controlled. This control should be based on physiological and behavioural data derived from birds at the most critical places in the system or animal house.

\section{References}

ANON (1992) Directive 92/40/EEC. Introducing Community measures for the control of avian influenza. Official Journal of the European Community 167, 1-16

ALEXANDER, D. J. (1995) The epidemiology and control of avian influenza and Newcastle disease. Journal of Comparative Pathology 112, 105-126 BOISSY, A. (1995) Fear and fearfulness in animals. Quarterly Review of Biology 70, 165-191

COENEN, A. M. L., DRINKENBURG, W. H. I. M., HOENDERKEN, R. \& VAN LUIJTELAAR, E. L. J. M. (1995) Carbon dioxide euthanasia in rats: oxygen supplementation minimizes signs of agitation and asphyxia. Laboratory Animal Sciences 29, 262-268

COENEN, A. M. L., SMIT, A., ZHONGHUA, L. \& VAN LUIJTELAAR, E. L. J.

M. (2000) Gas mixtures for anaesthesia and euthanasia in broiler chickens. World's Poultry Science Journal 56, 225-234

DANNEMAN, P. J., STEIN, S. \& WALSHAW, S. O. (1997) Humane and practical implications of using carbon dioxide mixed with oxygen for anesthesia or euthanasia of rats. Laboratory Animal Sciences 47, 376-385 GENTLE, M. J. \& TILSON, V. J. (2000) Nociceptors in the legs of poultry: implications for potential pain in pre-slaughter shackling. Animal Welfare 9, 227-239

GERRITZEN, M. A., LAMBOOIJ, E., REIMERT, H., STEGEMAN, A. \& SPRUIJT, B. M. (2004) On farm euthanasia of broiler chickens: effects of different gas mixtures on behavior and brain activity. Poultry Science $\mathbf{8 3}$, 1294-1301

HOEN, T. \& LANKHAAR, J. (1999) Controlled atmosphere stunning of poultry. Poultry Science 78, 287-289

KNOWLES, T. G. \& BROOM, D. M. (1990) The handling and transportation of broilers and spent hens. Applied Animal Behaviour Science 28, 75-91

LAMBOOIJ, E., GERRITZEN, M. A., ENGEL, B., HILLEBRAND, S. J. W. \& PIETERSE, C. (1999) Behavioral responses during exposure of broilers to different gas mixtures. Applied Animal Behaviour Science 62, 255-265

MATTSON, J. L., STINSON, J. M. \& CLARK, C. S. (1972) Electroencephalographic power-spectral changes coincident with the onset of carbon dioxide narcosis in rhesus monkeys. American Journal of Veterinary Research 33, 2043-2049

RAJ, A. B. M., WOTTON, S. B. \& GREGORY, N. G. (1992) Changes in the somatosensory evoked potentials and spontaneous electroencephalogram of hens during stunning with a carbon dioxide and argon mixture. British Veterinary Journal 148, 147-156

SCIENTIFIC VETERINARY COMMITTEE (1997) The Killing of Animals for Disease Control Purposes. Brussels, European Commission

SPARREY, J. M. \& KETTLEWELL, P. J. (1994) Shackling poultry: is it a welfare problem? World's Poultry Science Journal 50, 167-176 